\title{
The benefits of chewing gum in patients undergoing Ileocystoplasty
}

\author{
S. Capel \\ Royal National Orthopaedic Hospital, Brockley Hill, Stanmore, Middlesex, HA7 4LP, UK
}

\begin{abstract}
Ileocystoplasty is a surgical procedure involving utilisation of the ileum to reconstruct the bladder creating a capacious compliant low pressure structure. Patients often present with pre-existing complex co-morbidities; and prior to surgery their gastric motility is hampered by limited ambulation with the majority being wheelchair dependant. The physical manipulation of the bowel during the ileocystoplasty procedure can trigger a post operative ileus; a multifactorial inflammatory condition resulting in reduced gut transit time. This is compounded by anaesthesia and the use of opiod pain relief.

Following surgery the patients referred to the dietitian were repeatedly found to be slow to recover due to distressing symptoms preventing them from re-establishing eating at an early stage. The development of an ileus was a frequent occurrence and TPN used for most of the patients. A literature review was undertaken to investigate the hypothesis that chewing gum accelerates intestinal transit recovery $^{(1,2,3,4,5)}$, and has a stress relieving potential which may influence pain control ${ }^{(6,7)}$. A change in clinical practice was agreed with the urology team. Although not a definitive cure for early resolution of an ileus and improved gut transit time the literature indicated this was a safe procedure ${ }^{(8,9)}$. The main objectives were to improve patient symptoms post surgery, enabling them to re-establish eating and drinking earlier, avoid the need for TPN, enhance the post operative experience and subsequent recovery. All the patients admitted for elective ileocystoplasty surgery from November 2009 to March 2011 were included in this study. Referral to the dietitian was made on or before admission by the clinical nurse specialist. Patients were encouraged to chew sugar free chewing gum as soon as possible post surgery, provided they were safe to do so and there was minimal risk of aspiration. They were encouraged to chew for at least 30 minutes, three times a day until eating was established and their bowels had opened. Patients were asked by the clinical nurse specialist to supply the gum themselves and a variety of types were used. Records were maintained by the dietitian of the symptoms experienced post surgery, the time lapse before eating was re-established, the necessity for TPN, the initial response time and number of contacts made by the dietitian and the duration of their hospital stay. A retrospective review of the previous five years of patient dietetic records was under taken comparing the outcomes for patients who had undergone this procedure.

\begin{tabular}{|c|c|c|c|c|}
\hline Outcome & $\begin{array}{l}\text { Length of stay } \\
\text { (days) }\end{array}$ & $\begin{array}{l}\text { Requirement } \\
\text { for TPN }\end{array}$ & $\begin{array}{l}\text { Reported } \\
\text { symptoms }\end{array}$ & $\begin{array}{l}\text { No. of days to } \\
\text { re-establish eating }\end{array}$ \\
\hline $\begin{array}{l}\text { Patients not seen by the dietitian } \\
\text { Total } 18\end{array}$ & $\begin{array}{l}\text { Range } \\
6-50 \\
\text { Average } 13\end{array}$ & None & Unknown & Unknown \\
\hline $\begin{array}{l}\text { Delayed referral to the dietitian non gum users } \\
\text { Total } 12\end{array}$ & $\begin{array}{l}\text { Range } \\
7-41 \\
\text { Average } 19\end{array}$ & $\begin{array}{l}10 \text { patients } \\
\text { Total } 89 \text { days }\end{array}$ & $\begin{array}{l}\text { Total } 23 \\
\text { Range } \\
1-4 \\
\text { Average } 2\end{array}$ & $\begin{array}{l}\text { Range } \\
4-28 \\
\text { Average } 12\end{array}$ \\
\hline $\begin{array}{l}\text { Early dietetic intervention } \\
\text { Total } 7\end{array}$ & $\begin{array}{l}\text { Range } \\
8-31 \\
\text { Average } 14\end{array}$ & $\begin{array}{l}1 \text { patient } \\
\text { Total } 7 \text { days }\end{array}$ & $\begin{array}{l}\text { Total } 6 \\
\text { Range } 0-3 \\
\text { Average } 1\end{array}$ & $\begin{array}{l}\text { Range } \\
1-7 \\
\text { Average } 3\end{array}$ \\
\hline
\end{tabular}
\end{abstract}

Although this is a small study the changes in clinical practise demonstrated a benefit to both patients and the hospital. Earlier more frequent dietetic intervention and the use of gum have contributed to symptom relief enabling earlier re-establishment of eating post operatively. A considerable financial saving was achieved by avoiding TPN and reducing length of stay. During the course of this study evidence has grown emphasising the benefits of chewing gum to enhance bowel motility after abdominal surgery ${ }^{(10,11,12)}$, and this practice is now recommended by the European Association of Urology Nurses for procedures including ileocystoplasty ${ }^{(13)}$. It is postulated that the patients not referred to the dietitian may have experienced less symptoms post surgery enabling earlier re-establishment of eating, facilitating recovery ${ }^{(14)}$ and discharge. A retrospective examination of the medical records for the patients not referred to the dietitian would be useful to establish any differences in their treatment which could account for quicker recovery and earlier discharge; for example a medication comparison. Dissemination of the findings of this study to all the medical and nursing staff at RNOH is planned. This application has potential for consideration amongst other patient groups in this specialist setting suffering from the symptoms of delayed gastric transit time which affect their ability to meet their nutritional requirements particularly following spinal and orthopaedic surgery.

1. Schuster R et al. (2006) Arch Surg 141, 174-176.

2. Quah et al. (2006) Colorectal Disease 8, 64-70.

3. Chan MK (2007) Diseases of the Colon and Rectum 50 (12), 2149-2157.

4. Noble EJ (2009) International Journal of Surgery 7 (2), 100-105.

5. (2006) J A M Coll Surg May 202 (5), 773-8.

6. Mohni Y (Nov 2005) Journal of the International Association for the study of Pain 118 (1), 35-42.

7. Scholey (2009) Physiology and Behaviour (97) 304-312.

8. Vasquez et al. (2009) Journal of Gastrointestinal Surgery 13, 649-656.

9. Edward J World Journal of Surgery 2557-2566.

10. Acta Chir Belg (2010) Mar-April 110 (2), 195-9.

11. Hocevar et al. (2010) Journal of Wound Ostomy and Continence Nursing. March/April 37 (2), 140-146.

12. Chan MK et al. (2011) National Institute for Health Research.

13. Eaun (2010) European Ass Of Urology Nurses. Good Practice in Health care.

14. (2004) Curr Opin Clin Nut Metab Care 7 (5), 577-83. 